\title{
Research Article - Microbiology \\ Community analysis of soil nematodes in vegetable growing areas of Dhading District, a high hill of Nepal
}

\author{
A.K. Keshari ${ }^{1}$, M. Manjur Shah ${ }^{2 *}$, R. Gupta ${ }^{3}$ \\ ${ }^{1}$ Dept. of Department of Zoology, Patan M. Campus, Tribhuvan University, Nepal \\ ${ }^{2}$ Department of Biological Sciences, Faculty of Science, Yusuf Maitama Sule University, Kano State, Nigeria \\ ${ }^{3}$ Head, Central Department of Zoology, Tribhuvan University, Nepal
}

(Received: 28-09-2018; Accepted 27-10-2018; Published Online 04-11-2018)

*Corresponding author (E-mail: mmanjurshah@gmail.com)

\begin{abstract}
A nematological survey was carried out in the year 2014 from vegetable crops of Dhading district; a high hill of Nepal located at latitude $2752^{\prime} 0.120^{\prime \prime} \mathrm{N}$, longitude $8455^{\prime} 0.120$ "E and altitude $1518 \mathrm{~m}$. The entire district covers mainly temperate zone with annual average precipitation and temperature $1683.9 \mathrm{~mm}$ and $11.8-22.4^{\circ} \mathrm{C}$ respectively. Thirty soil samples were collected randomly from ten vegetable crops during their flowering time. A total of 23 genera of soil inhabiting nematodes belonging to 7 orders and 14 families were encountered. Of the total population, herbivores were 33\%, bacteriovores $35 \%$, fungivores $12 \%$, predators $14 \%$ and omnivores $6 \%$. In terms of number of genera varied from 8 to 14 and in terms of abundance the number varied from 64 to 308 per $100 \mathrm{cc}$ of soil. Rhabditis was the most abundant genus among bacteriovores, Aphelenchoides among fungivores, Mononchus among predators and Helicotylenchus among herbivores. Meloidogyne sp was the most dominant plant parasitic nematode in terms of both frequency and density occurring in many vegetable crops. The trophic diversity index (TDI) in the sample was $1.07-1.30(1.16 \pm 0.06)$, maturity index (MI) $1.66-$ $2.65(2.22 \pm 0.25)$, plant parasitic index (PPI) $2.49-3.0(2.95 \pm 0.11)$ and channel index (CI) $0.21-1.48(0.82 \pm 0.35)$.
\end{abstract}

Keywords: Soil nematodes, frequency, abundance, generic diversity, ecological indices, vegetable crops, Nepal

\section{Introduction}

Soil nematodes may vary from pristine to extremely pollute. They interact with biotic and abiotic factors of soil ecosystem. These are important for maintaining soil functionality and regulating processes that support ecosystem services, like nutrient, water retention and carbon storage (Bradford et al., 2007). The association of soil nematodes of different trophic groups including plantparasitic nematodes is important for the vegetable crop production. The free-living nematodes are important for plant productivity (Yeates and Coleman, 1982). However, plant-parasitic nematodes often cause economic damage, therefore, they are of special interest to many producers. The damage potential associated with plant parasitic nematodes in a crop is mostly estimated by their numbers in the soil at planting time.

Soil microfauna depend on plant and other resources, including organic and green manures. Amendments in soil increase fertility and organic matter may suppress root diseases by increasing the levels of predaceous microorganisms in the soil (Clark et al., 1998). The composition of nematode communities (free-living and plant-parasitic) and the genera, species and abundance (number) of soil nematodes may be used as bioindicators of soil health (Neher, 2001).

Several ecological indices such as trophic diversity index (TDI), maturity index (MI), plant parasitic index (PPI) and channel index (CI) have been applied to assess the nematode community dynamics and role of nematodes in the agro ecosystem. Although, nematode community composition varies with differences in soil types and soil $\mathrm{pH}$ (Mulder et al., 2003). Although a number of studies have been done on soil nematode communities in other countries, but very limited work regarding community analysis of soil nematodes is done in Nepal. It is the first study on community analysis of soil nematodes in Nepal. The aim of present study was to investigate nematode communities associated with vegetable crops of Dhading, a vegetable growing hilly district of Nepal.

\section{Materials and methods}

\section{Site description}

The survey site was the vegetable growing field in the village Benighat of Dhading District located about forty $\mathrm{km}$ in the southern part of the capital city, Kathmandu valley. Study was done in July 2014 to Dec 2014. The entire area of Dhading is covered by hills and deep slopes. The characteristics of study site are reported in Table 1 .

Table 1: Characteristics of study site

\begin{tabular}{lc}
\hline Characteristics & Specification of study site \\
\hline Altitude & $1518 \mathrm{~m}$ \\
Latitude & $2752^{\prime} 0.120 " \mathrm{~N}$ \\
Longitude & $8455^{\prime} 0.120^{\prime \prime} \mathrm{E}$ \\
Average annual precipitation* & $1683.9 \mathrm{~mm}$ \\
Average annual temperature* & $11.8-22.4^{\circ} \mathrm{C}$ \\
Soil pH & 6.68 \\
Carbon \% & 2.85 \\
Nitrogen \% & 0.16 \\
C:N ratio & 18.0 \\
\hline
\end{tabular}

* Source: Dept. of Hydrology \& Meteorology, Govt. of Nepal, 2013-14 


\section{Soil sampling and processing}

Thirty soil samples were collected at random from rhizospheres of ten vegetable crops - potato (Solanum tuberosum), cauliflower (Brassica oleracea), tomato (Lycopersicum esculentum), brinjal (Solanum melagena), cucumber (Cucumis sativus), garlic (Allium sativum), soybean (Glycine max), radish (Raphanus sativus), pumpkin (Cucurbita pepo) and cabbage (Brassica oleracea) commonly grown in Dhading district.

Five sub-samples collected randomly from a depth of 10-15 cm from each vegetable crop were mixed to make a composite sample. A 100cc of soil sample from collected sample was processed by Cobb's sieving and decantation and modified Baermann's funnel technique for extraction of nematodes.

\section{Determination of $\mathrm{pH}$, nitrogen and Carbon content}

Soil $\mathrm{pH}$, total nitrogen and organic carbon content present in soil (Table 1) were determined using standard protocol in an Agricultural Technology Center (a Government registered private laboratory), Pulchowk, Lalitpur, Nepal.

Identification of nematode genera and nematode trophic groups

Identification of soil nematodes upto generic level was done using the keys by Mai and Lyon (1975), Ahmad (1996) and Ahmad and Jairajpuri (2010). Five trophic groups viz., bacteriovores, fungivores, omnivores, predators and herbivores were allocated according to Yeates et al. (1993).

\section{Counting of nematode genera}

Nematodes as collected above were counted by using a counting disc under stereoscopic binocular microscope. An aliquot of one $\mathrm{ml}$ suspension was taken by pipette from 10 $\mathrm{ml}$ of nematode suspension into a counting disc in order to count the various genera of free living and plant parasitic nematodes. After three readings, the mean of the replicates for each nematode genus was taken which was further multiplied by $10 \mathrm{ml}$ in order to determine mean number of individuals of each genus in a sample. Data were used for further statistical analysis.

\section{Statistical analysis}

Parameters for community analysis of various nematode genera were calculated using formulae by Norton (1978).

Frequency $(N)$ : Frequency of nematode genus (i. e. the number of samples in which the genus was present).

Absolute Frequency (AF \%): (Frequency of the genus) $\times$ $100 /$ total number of samples counted.

Density $(D)$ : Number of nematode specimens of the genus counted in all samples / total number of the samples collected.

Relative Density (RD \%): Mean density of the genus $\times 100 /$ sum of mean density of all nematode genera.

Maturity Index (MI)

$$
M I=\sum_{i=1}^{n} V(i) \cdot f(i)
$$

Where $\mathrm{Vi}=\mathrm{cp}$ value of the ith taxon. f(i) the frequency of that taxon in a sample

Plant Parasitic index (PPI)

$$
P P I=\sum P P i X i / \sum X i
$$

Where, Ppi $=$ PP value assigned to taxon $\mathrm{i}$ according to Bongers (1990).

$\mathrm{Xi}=$ abundance of taxon $\mathrm{i}$ in the sample.

Channel index $(C I)=100 \times 0.8 \mathrm{Fu}_{2} /\left(3.2 \mathrm{Ba}_{2}+\mathrm{Fu}_{2}\right)$

Trophic Diversity index $(T D I)=1 / \sum \mathrm{pi}^{2}$

where $\mathrm{pi}^{2}$ is the proportional contribution of $\mathrm{i}_{\text {th }}$ trophic group.

Statistical calculations were done using computer program STATISTICA.

\section{Results}

\section{Diversity of nematode genera}

In the present study, a total of twenty three genera of soil nematodes belonging to seven orders and twenty families were encountered from the vegetable crops of Dhading district. Number of genera per $100 \mathrm{~cm} 3$ soil sample varied from 8 to 14 . In terms of abundance, the number of individual varied from 64 to 308 in per $100 \mathrm{cc}$ of soil. Rhabditis was the most abundant genus among bacteriovores, Aphelenchoides among fungivores, Mononchus among predators, Dorylaimus among omnivores and Helicotylenchus among herbivores.

In terms of taxonomic group among the twenty three genera identified, the Order Tylenchida represented 39\% with 9 genera under 6 families, followed by Rhabditida $31 \%$ with 7 genera under 3 families, Mononchida $13 \%$ with 5 genera under 4 families, Aphelenchida 9\% with 2 genera under 2 families, Araeolaimida $4 \%$ and Dorylaimida $4 \%$ with 1 genera under 1 family each (Fig. 2D). While studying the ordinal diversity in terms of abundance, the Order Tylenchida was $36 \%$ followed by Rhabditida 33\%, Mononchida 13\%, Aphelenchida 10\%, Araeolaimida 2\% and Dorylaimida 6\% (Fig. 2C).

\section{Trophic diversity}

Nematode genera were allocated to different trophic groups according to their feeding habits, viz. bacteriovores, fungivores, herbivores, omnivores and predators. In the present study, in terms of number of genera, bacteriovores constituted the most dominant group with 8 genera followed by 7 genera of herbivores, 3 genera of predators, 4 genera of fungivores and one genus of omnivores (Fig.1B). In terms of number of individuals, bacteriovores represented most abundant trophic group with $35 \%$ followed by herbivores $(33 \%)$, predators $(14 \%)$, fungivores $(12 \%)$ and omnivores (6\%) (Fig.1A). Among herbivores, the genus Helicotylenchus was most dominant genus while Rhabditis, Aphelenchoides, Mononchus were most dominant genera among bacteriovores, fungivores and predators respectively. Least dominant genera among herbivores, bacteriovores, fungivores and predators were Boleodorus, Plectus, Filenchus and Iotonchus respectively (Table 2). The abundance of bacteriovores in the samples ranged 23-113, followed by fungivores 6-7, herbivores 10-106, omnivores 0 - 20 and predators 6-53. The trophic diversity index (TDI) 
in the study area ranged from 1.07-1.30 $(1.16 \pm 0.06)$ (Table $3)$.

\section{Nematodes frequency}

Analyzing the frequency of soil inhabiting nematodes of vegetable crops, Rhabditis was the most frequent genus among the bacteriovores with a frequency of 29/30 and absolute frequency (AF) 96.7\%, whereas Plectus and Zeldia were least frequent $7 / 30$, with AF $23.3 \%$ each. Similarly, among fungivores, Aphelenchoides was the most frequent genus with a frequency $25 / 30$ and $\mathrm{AF} 83.3 \%$, whereas Filenchus was least frequent $2 / 30$ and AF $6.7 \%$.

Among the seven genera of plant parasitic nematodes recorded, Helicotylenchus was the most frequent genus $30 / 30$ with an AF $100 \%$ whereas Boleodorus 3/30 with an $\mathrm{AF}$ was least frequent. Among three genera of predators, Mononchus was most frequent 24/30 and absolute frequency of $80.0 \%$, whereas Iotonchus was least frequent $13 / 30$ and AF $43.3 \%$ (Table 2).

Table 2: Population structure of soil inhabiting nematodes of vegetable crops of Dhading district

\begin{tabular}{|c|c|c|c|c|}
\hline Genera & $\mathbf{N}$ & AF\% & MD & RD\% \\
\hline \multicolumn{5}{|l|}{ Bacteriovores } \\
\hline Mesorhabditis & 16 & 53.3 & 7 & 4.1 \\
\hline Rhabditis & 29 & 96.7 & 15.1 & 9.0 \\
\hline Eucephalobus & 20 & 66.7 & 7.5 & 4.5 \\
\hline Acrobeloides & 21 & 70.0 & 7.6 & 4.5 \\
\hline Cephalobus & 20 & 66.7 & 9.8 & 5.8 \\
\hline Eucephalobus & 12 & 40.0 & 4.1 & 2.4 \\
\hline Zeldia & 7 & 23.3 & 4.6 & 2.7 \\
\hline Plectus & 7 & 23.3 & 3.4 & 2.0 \\
\hline \multicolumn{5}{|l|}{ Fungivores } \\
\hline Aphelenchus & 21 & 70.0 & 6.0 & 3.5 \\
\hline Aphelencoides & 25 & 83.3 & 10.4 & 6.2 \\
\hline Tylenchus & 8 & 26.7 & 3.2 & 1.9 \\
\hline Filenchus & 2 & 6.7 & 1.1 & 0.7 \\
\hline \multicolumn{5}{|l|}{ Omnivores } \\
\hline Dorylaimus & 26 & 86.7 & 10.3 & 6.1 \\
\hline \multicolumn{5}{|l|}{ Herbivores } \\
\hline Psilenchus & 5 & 16.7 & 2.0 & 1.2 \\
\hline Boleodorus & 3 & 10.0 & 1.8 & 1.1 \\
\hline Helicotylenchus & 30 & 100.0 & 17.4 & 10.3 \\
\hline Tylenchorhynchus & 18 & 60.0 & 9.0 & 5.3 \\
\hline Hoplolaimus & 5 & 16.7 & 2.6 & 1.5 \\
\hline Meloidogyne & 18 & 60.0 & 20.6 & 12.2 \\
\hline Criconematids* & 9 & 30.0 & 2.9 & 1.7 \\
\hline \multicolumn{5}{|l|}{ Predators } \\
\hline Mononchoides & 16 & 53.3 & 7.1 & 4.22 \\
\hline Iotonchus & 13 & 43.3 & 4.6 & 2.72 \\
\hline Mononchus & 24 & 80.0 & 10.9 & 6.47 \\
\hline
\end{tabular}

$\mathrm{N}$ (Frequency) = No. of samples in which the genus was present; AF\% = Frequency of genus $\mathrm{x} 100 /$ total no. of sample (i.e. 30 ); MD = Total no. of specimens of a genera / No. of samples; RD \% = Mean density of a genus x100 / sum of mean density of all nematode genera; * - include all genera of family Criconemtidae

Table 3: Nematode community indices of vegetable crops of Dhading district

\begin{tabular}{lc}
\hline Nematode & Values \\
\hline Index & \\
Trophic diversity index (TDI) & $1.07-1.30(1.16 \pm 0.06)$ \\
Maturity index (MI) & $1.66-2.65(2.22 \pm 0.25)$ \\
Plant parasitic index (PPI) & $2.49-3.0(2.95 \pm 0.11)$ \\
Channel index (CI) & $0.21-1.48(0.82 \pm 0.35)$ \\
\hline
\end{tabular}

\section{Mean density}

In terms of mean density of soil nematodes, among bacteriovores, Rhabditis was the most dominant genus with a mean density (MD) 15.1 per soil sample and relative density (RD) $9.0 \%$. Least dominant genera were Plectus and Zeldia with MD 3.4 per soil sample and RD 2.0\%. Among fungivores, Aphelenchoides was the most dominant genus ( $\mathrm{MD}=17.4$ and RD 10.3\%). Similarly, Helicotylenchus was most dominant genus among herbivores with MD 10.4 and RD 6.2\% and Mononchus was the most dominant genus among predators with MD 10.9 per soil sample and RD 6.47\% (Table 2).

\section{Nematode community dynamics}

The diversity of nematode fauna in agroecosystems and their relationship to soil processes suggests that they are potential bioindicators. For assessing the community dynamics and role of nematodes in agrosystem, various community indices were calculated. In the present study, the trophic diversity index (TDI) was 1.07-1.30 (1.16 \pm 0.06$)$, maturity index (MI) 1.66-2.65 (2.22 \pm 0.25$)$, plant parasitic index (PPI) 2.49-3.0 (2.95 \pm 0.11$)$ and channel index (CI) 0.21-1.48 (0.82 \pm 0.35$)$ (Table 3).

\section{Discussion}

Soil nematodes are ubiquitous and important soil inhabitants. Although nematodes co-exist together in different ecosystems (Boag and Yeates, 1998), their frequency, density and diversity vary depending upon ecological and edaphic factors (Khatoon et al., 2001). Soil mineral concentration, soil type, pore spaces and root exudates could be other factors, which influence generic coexistence and density of nematodes. Present study 
revealed a great deal of trophic and generic diversity within entire nematode community of vegetable growing areas. Among a total of 23 genera identified, bacteriovores representing 8 genera, herbivores (7 genera), omnivores (1genera), fungivores (4 genera) and predators (3 genera).
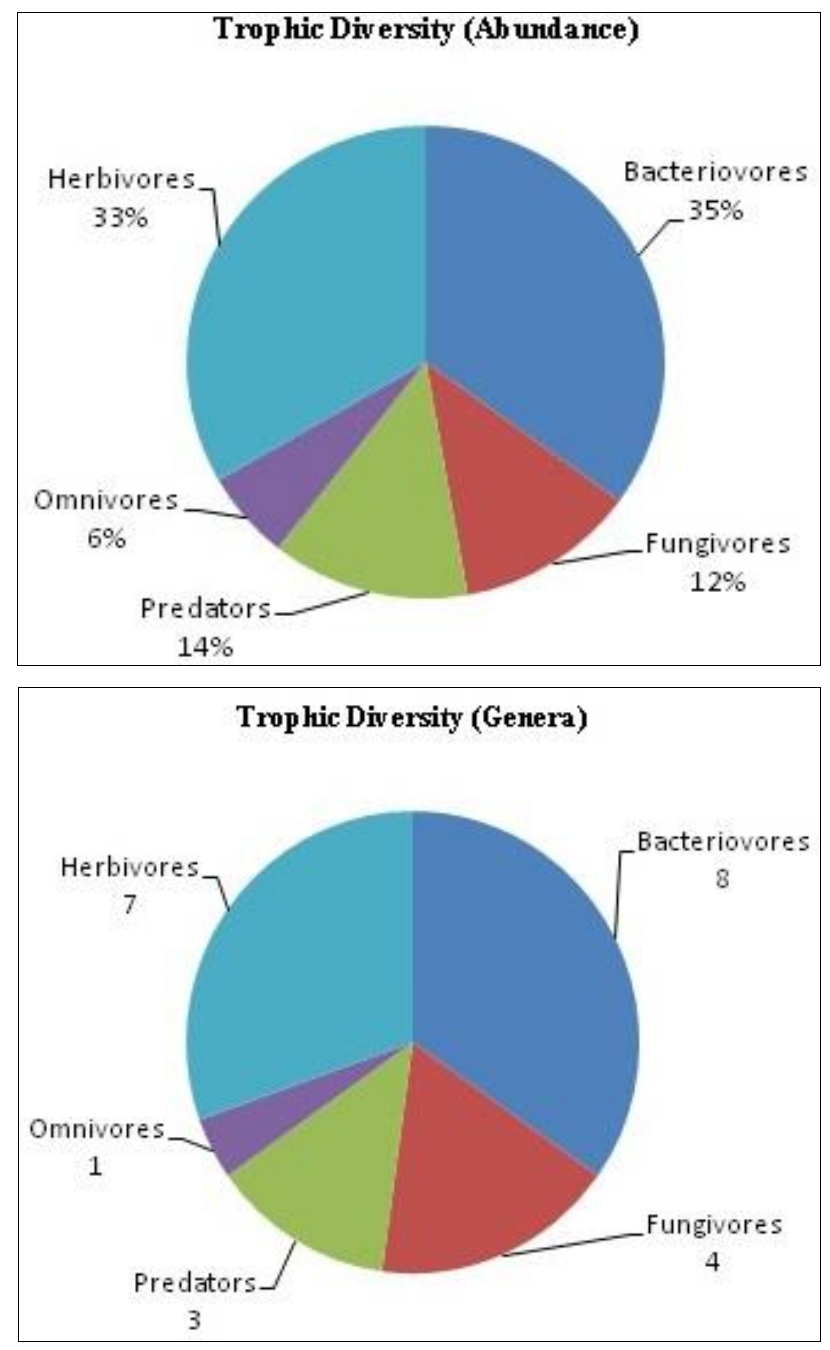

Fig1. Trophic diversity (abundance and genera) in vegetable field (A \& B)

Among these, the plant-parasitic nematode (PPN) group causes economic damage to crop plants and the free-living group can indicate soil health and/or quality (Ferris et al., 2001). The importance of plant-parasitic nematode genera in vegetable crops can be indicated by their density (nematode numbers per unit soil) and frequency (the occurrence of a specific genus in the samples collected from each crop). From an agricultural perspective, the PPN density is used to determine the economic damage potential and resulting need for nematode management strategies; thus density is more important than frequency. Nematode frequency, used to determine the distribution pattern, can help to establish the importance of the nematodes present in a location. In our study, nematode genera with their frequency were considered common for the locality and crop, but their importance was determined based on both frequency and abundance.

As a trophic group, herbivores dominated other nematode communities. This result was similar to the report of Liang $e t$ al., 1999. Similarly, present study showed mean nematode density at 0.3-23.6 which was almost similar to the report of Freckman and Ettema, 1993. As a nematode community, herbivore nematodes dominated other nematode communities viz., bacteriovores, omnivores, fungivores and predators. Phytophagous nematodes are the best known of the soil organisms because of the damage they cause to agricultural crops; such as decreasing plant production, disrupting plant nutrient and water transfer, besides decreasing the quantity and quality of the produce. In agricultural soils, greater diversity of trophic groups may be correlated with an increase in the frequency of less abundant trophic groups e.g., fungivorous, omnivorous and predators relative to that of generally more abundant trophic groups, for example, bacteriophagous / free living and phytophagous (Neher, 2001).
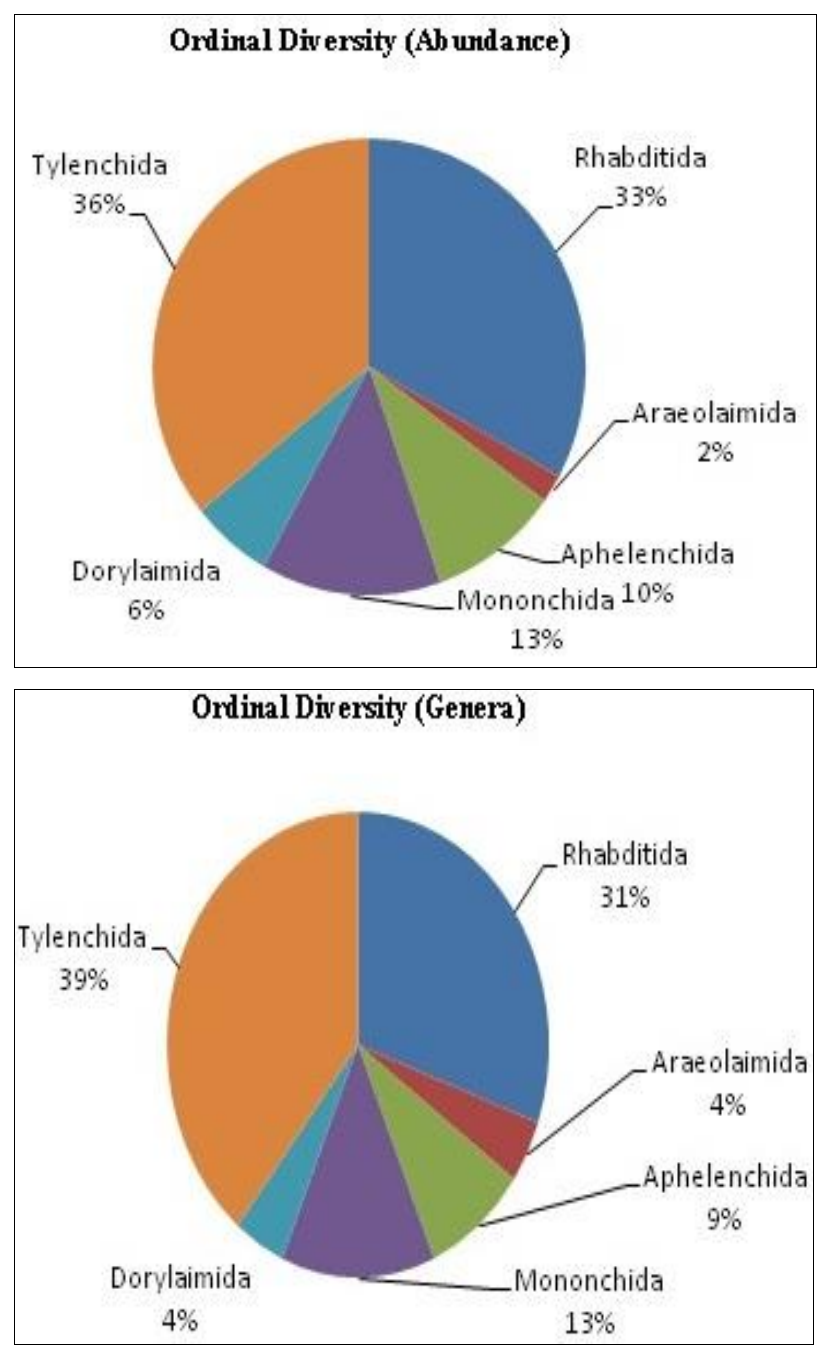

Fig 2. Ordinal diversity (abundance and genera) in vegetable field $(C \& D)$

Present study showed that the root-knot nematode (Meloidogyne sp.) significantly higher in tomato, brinjal, cucumber, cauliflower, pumpkin and cabbage and thus, possibly considered as the potentially damaging nematode species. Among ectoparasites, Helicotylenchus sp. had high population in both frequency and density in all studied plant species, however, its exact role in vegetable production is not well known. The reason for higher herbivore populations could be their small body structure and easy availability of food. Bacteriovores were dominant and frequent next to herbivores.

The reason of dominance of bacterial feeders in this study might due to use of fertilizers and other manures by the farmers. This increases the number of nematodes that are capable of responding quickly to increased food supply and 
therefore, increase the enrichment index. Increased nutrient availability may increase root growth, which in turn may increase the resources available for the herbivores nematodes.

The channel index (CI) provides a means of flow of resources through fungal and bacterial decomposition channel in the soil food web (Bongers, 1990). In the present study, CI was consistently low (ranging between 0.63 and 0.82 ) in the studied area. This low CI indicated a lower dominance of the bacterial decomposition pathway (Ugarte, 2013). However, a high CI is possible in highly disturbed agroecosystems as well as in undisturbed natural ecosystems (Berkelmans et al., 2003). The low CI in vegetable soils may indicate that vegetable production systems have a lesser abundance of bacterial decomposition with associated bacterial-feeding nematodes. To provide a healthy soil ecosystem with adequate soil fertility, enrichmentopportunists (bacterivorous nematodes) should be maintained at a high level (Ferris and Matute, 2003).

The free-living nematodes improve soil health and ultimately crop production. The maturity index (MI) measures the level of disturbance of soil ecosystem. Lower values $(<2.0)$ indicate more disturbances and higher values ( \pm 4.0) a stable or pristine environment (Bongers, 1990). In the present study, MI ranged from 1.66-2.65 which indicated the habitat to be moderately stable and undisturbed.

The PPI is very good indicator of plant parasitic nematode resource. It is computed only for plant-feeding nematodes with the rationale that their abundance is determined by vigor of their host plants, which in turn, is determined by system enrichment. In the present study, PPI ranges between 2.49-3.0 which agrees with the earlier report of Neher and Campbell (1994) which estimated PPI value as 2.82 and 2.51 in soybean plantations.

\section{References}

Ahmad, W. (1996). Plant parasitic nematodes of India: An identification Manual. Aligarh, India: Department of zoology, Aligarh Muslim University, 347pp.

Ahmad, W., and Jairajpuri, M.S. (2010). Mononchida, the Predatory Soil Nematodes. Nematology Monographs and Perspectives Vol 7, Boston, Brill Leiden.

Berkelmans, R., Ferris, H., Tenuta, M., and Van Bruggn, A.H.C. (2003). Effects of long-term crop management on nematode trophic levels other than plant feeders disappear after 1 year of disruptive soil management. Applied Soil Ecology, 23, 223-235.

Boag, B., and Yeates, G.W. (1998). Soil nematode biodiversity in terrestrial ecosystem. Biodiversity and Conservation, 7, 617-630.

Bongers, T. (1990). The maturity index: an ecological measure of environmental disturbance based on nematode species composition. Oecologia, 83, 14-19.

Bradford, M.A., Tordoff, G.M., Black, H.I.J., Cook, R., Eggers, T., and Garnett, M.H., (2007). Carbon dynamics in a model grassland with functionally different soil communities. Functional Ecology, 21, 690-697.
Clark, M.S., Ferris, H., Klonsky, K., Lanini, W.T., Van Bruggen, A.H.C., and Zalom, F.G. (1998). Agronomic, economic, and environmental comparison of pest management in conventional and alternative tomato and corn systems in northern California. Agriculture, Ecosystem and Environment, 68, 51-71.

Ferris, H., Bongers, T. and Goede, R.H.M. de (2001). A framework for soil food web diagnostics: extension of the nematode faunal analysis concept. Applied Soil Ecology, 18, 13-29.

Ferris, H., and Matute, M.M. (2003). Structural and functional succession in the nematode fauna of a soil food web. Applied Soil Ecology, 23, 93-110.

Freckman, D.W., and Ettema, C.H. (1993). Assessing nematode communities in agroecosystem of varying human intervention. Agriculture, Ecosystem and Environment, 45, 239-261.

Khatoon, M., Sharma, S., and Saxena, S.K. (2001). Community analysis of predatory nematodes of Rohilkhand division. UP. Current Nematology, 12,1114.

Liang, W., Lavian, I., and Steinbertger, Y. (1999). Dynamics of nematode community composition in potato field. Pedobiologia, 43, 459-469.

Mai, W.F., and Lyon, H.H. (1975). Pictorial Key to Genera of Plant Parasitic Nematodes. $4^{\text {th }}$ edition, Revised. Ithaca and London, Comstock Publishing Associates, Cornell University Press. pp219.

Mulder, C.H., De Zwart, D., Van Wijnen, H.J. , Schouten, A.J., and Breure, A.M. (2003). Observational and simulated evidence of ecological shifts within the soil nematode community of agroecosystems under conventional and organic farming. Functional Ecology, 22, 516-525.

Neher, D.A. (2001). Role of nematodes in soil health and their use as indicators, Journal of Nematology, 33, 161168.

Neher, D.A., and Campbell, C.L. (1994). Nematode communities and microbial biomass in soils with annual and perennial crops. Applied Soil Ecology, 1, 17-28.

Norton, D.C. (1978). Ecology of plant parasitic nematodes. New York : John Willey and Sons. pp268.

Ugarte, C., Zaborski, E.R., and Wander, M.M. (2013). Nematode indicators as integrative measures of soil condition in organic cropping systems. Soil Biology and Biochemistry, 64, 103-113.

Yeates, G.W., Bongers, T., Goede, R.G.M., Freckman, D.W., and Georgieva, S.S. (1993). Feeding habits in soil nematode families and genera - an outline for soil ecologists. Journal of Nematology, 25(3), 315-331.

Yeates, G.W., and Coleman, D.C. (1982). Nematodes in decomposition, In: D.W. Freckman (Ed.), Nematodes in soil ecosystems, University of Texas Press, Austin. pp 55-80. 